\title{
Contribution of general practitioners to hospital intrapartum care in maternity units in England and Wales in 1988
}

\author{
Lindsay F P Smith, David Jewell
}

\begin{abstract}
Objective-To ascertain the contribution of general practitioners to hospital intrapartum care in 1988.

Design-Confidential postal questionnaire.

Setting-All maternity units in England and Wales.

Main outcome measures-Type of general practitioner unit (if any); number of bookings, transfers, and deliveries by general practitioners; participation of general practitioners in the policy and audit of the unit.
\end{abstract}

Results -277 (93\%) of 297 units replied. Of 611644 deliveries, $36043(5.9 \%)$ were under general practitioner care. In all, 228 units permitted general practitioners to book women under their sole care: 65 were isolated, 29 alongside, and 134 integrated general practitioner units. Alongside units had significantly more bookings (568), antenatal transfers (69), intrapartum transfers (86), and deliveries (387) compared with isolated units $(185,18,16$, and 125 , respectively) and integrated units $(106,18,18$, and $52)(p<0.001$ for all differences). The percentage of women booked by general practitioners transferred either before or during labour was independent of both the type of unit and the number of general practitioner bookings. General practitioners in consultant units were significantly less likely to attend meetings reviewing perinatal mortality $(\mathbf{p}<0.01)$, and these units were less likely to have any form of general practitioner-consultant liaison committee $(p<0.001)$ compared with general practitioner units as a whole. Compared with those in isolated and alongside units, general practitioners in integrated units were less likely to have taken part in deciding the unit's booking policy $(p<0.01)$ and consultants more likely to be the final determinant of whether a general practitioner should be permitted to practice within the unit $(\mathbf{p}<0.001)$.

Conclusions-Both the number of deliveries booked by general practitioners and the number of isolated general practitioner units have fallen. Transfer from general practitioner to consultant care was independent of the general practitioner unit's caseload or the type of unit. General practitioner units differ from consultant units in important ways and differ among themselves as well. Except in remote areas, alongside units may be the ideal type of unit to encourage general practitioners to continue to provide intrapartum care.

\section{Introduction}

Complete obstetric care used to be an essential part of British general practice, but the number of women delivering under the care of their family doctor has steadily decreased from more than $85 \%$ in $1927^{1}$ through $50 \%$ in $1946^{2}$ to about $15 \%$ in $1975 .{ }^{3}$ This fall has accompanied the increase in institutional delivery ${ }^{3}$ and the decrease in the number of general practitioners providing intrapartum care. ${ }^{4}$

Details of all deliveries in England and Wales are published annually by the Office of Population Censuses and Surveys, ${ }^{5}$ and are classified by type of NHS hospital as isolated general practitioner hospital or as other NHS hospital, in which group they are not subclassified as general practitioner or consultant units. The figures do not show the total number of deliveries occurring under general practitioner care.

Several papers document the obstetric workload of general practitioners in individual units ${ }^{6.9}$ and even in groups of isolated units, ${ }^{10} 11$ but the number of units in which general practitioners provide intrapartum care and the workload within those units have not been described. To measure general practitioners' involvement in the provision and audit of hospital intrapartum care we surveyed all maternity units in England and Wales. This paper reports general practitioner deliveries, transfer rates, interaction between general practitioners and consultants, support facilities, and variation according to type of general practitioner unit.

\section{Methods}

The names and addresses of all maternity units in England and Wales were obtained from the 14 English regional health authorities and the Welsh Office. A confidential questionnaire was sent to the unit general manager responsible for each maternity unit in September 1989, asking about activities in 1988: number and type of deliveries; type of hospital (and general practitioner unit if any); number of patients transferred from general practitioner to consultant care; number of consultants and general practitioners working in the unit and the interaction between them; support facilities; and training taking place in the unit. Each unit was asked to define itself as either a general practitioner unit of one of three types: isolated (geographically separate), alongside (functionally separate with own ward and delivery area, either within consultant unit or adjacent to it), or integrated (using common wards and delivery areas with consultant cases)-or as a consultant unit (no cases booked by general practitioners for hospital midwife delivery).

The returned questionnaires were analysed by nonparametric methods: the Kruskall-Wallis test (to generate the $\mathrm{H}$ statistic) followed by the MannWhitney test to compare groups if the $\mathrm{H}$ value indicated significance, and Spearman's rank correlation or $\chi^{2}$ test as appropriate. Significance was defined as $\mathrm{p}<0 \cdot 01$ to allow for the large number of comparisons.

\section{Results}

In all, 312 maternity units were identified by the regional health authorities and the Welsh Office; of these, three had no intrapartum facilities and 12 had

Dr Smith. 


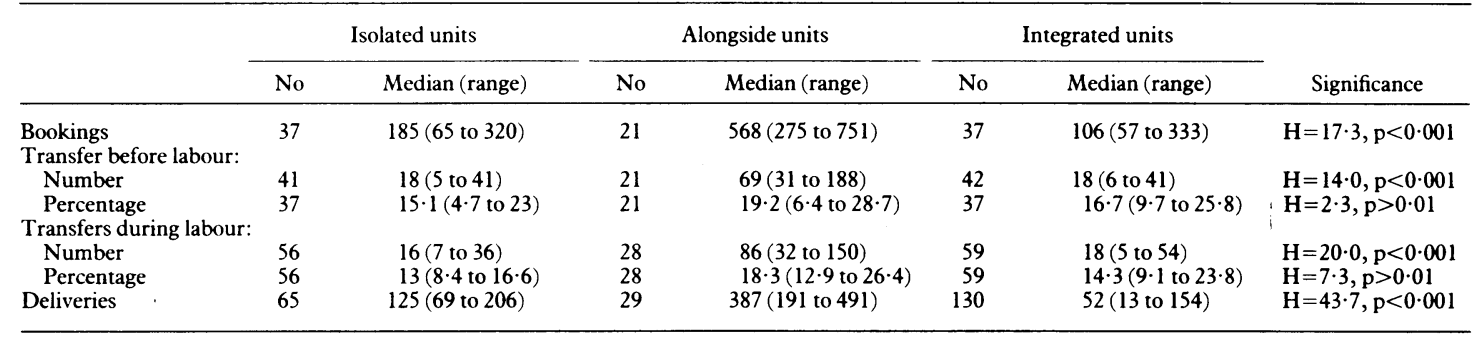

TABLE II-Number (percentage) of maternity units with general practitioner (GP) and consultant involvement

\begin{tabular}{|c|c|c|c|c|c|c|}
\hline & \multicolumn{3}{|c|}{ General practitioner units } & \multirow{2}{*}{$\begin{array}{c}\text { Consultant } \\
\text { units }\end{array}$} & \multirow[b]{2}{*}{$\mathrm{p}$ Value } & \multirow[b]{2}{*}{$\chi^{2}$} \\
\hline & Isolated & Alongside & Integrated & & & \\
\hline \multicolumn{7}{|c|}{ GP consultant liaison committee: } \\
\hline Yes & $40(65)$ & $25(89)$ & $105(81)$ & $14(40)$ & $\mathrm{p}<0.001$ & $28 \cdot 7(\mathrm{df}=3)$ \\
\hline No & $22(35)$ & $3(11)$ & $25(19)$ & $21(60)$ & & \\
\hline Not known & 3 & 1 & 4 & 14 & & \\
\hline \multicolumn{7}{|c|}{ GP input to unit's audit: } \\
\hline Yes & $20(51)$ & $7(33)$ & $11(13)$ & $3(10)$ & $\mathrm{p}<0.001$ & $24.9(\mathrm{df}=3)$ \\
\hline No & $19(49)$ & $14(67)$ & $71(87)$ & $26(90)$ & & \\
\hline Not known & 6 & 1 & 12 & 6 & & \\
\hline \multicolumn{7}{|c|}{ GP input to perinatal mortality meetings: } \\
\hline Yes & $18(53)$ & $15(58)$ & $47(35)$ & $9(19)$ & $\mathrm{p}<0.01$ & $15 \cdot 1(\mathrm{df}=3)$ \\
\hline No & $16(47)$ & $11(42)$ & $86(65)$ & $38(81)$ & & \\
\hline Not known & 12 & 2 & 1 & 2 & & \\
\hline \multicolumn{7}{|c|}{ GP approved to practise in unit by: } \\
\hline Consultant & $8(20)$ & $5(26)$ & $68(61)$ & & $\mathrm{p}<0.001$ & $40 \cdot 5(\mathrm{df}=4)$ \\
\hline GP & $32(80)$ & $14(74)$ & $23(39)$ & & & \\
\hline Other & 8 & 5 & 20 & & & \\
\hline \multicolumn{7}{|c|}{ GPs involved in deciding unit's booking policy: } \\
\hline Yes & $37(70)$ & $19(83)$ & $49(49)$ & & $\mathrm{p}<0.01$ & $12 \cdot 5(\mathrm{df}=2)$ \\
\hline No & $16(30)$ & $4(17)$ & $52(51)$ & & & \\
\hline Not known & 12 & 6 & 33 & & & \\
\hline \multicolumn{7}{|c|}{ GPs permitted to perform lift-forceps: } \\
\hline Yes & $47(82)$ & $14(48)$ & $49(42)$ & & $\mathrm{p}<0.001$ & $25 \cdot 9(\mathrm{df}=2)$ \\
\hline No & $10(18)$ & $15(52)$ & $68(58)$ & & & \\
\hline Not known & 8 & & 17 & & & \\
\hline
\end{tabular}

closed before the end of 1988 . Of the remaining 297 units, 277 (93\%) replied: 65 isolated, 29 alongside, and 134 integrated general practitioner units and 49 consultant units. Of the 20 non-responders, 11 had general practitioner deliveries; therefore we received replies from $95 \%$ of the general practitioner units in England and Wales.

\section{DELIVERIES}

A total of 611644 deliveries were reported in this survey, representing $91 \%$ of the published figure of 673972 for England and Wales in $1988 . .^{5}$ Of these, $36043(5.9 \%)$ were deliveries booked for hospital general practitioner care. Of the general practitioner deliveries, $9782(27 \cdot 1 \%)$ occurred in isolated general practitioner units, $11027(30 \cdot 6 \%)$ in alongside general practitioner units, and $15234(42 \cdot 3 \%)$ in integrated general practitioner units.

The median number of deliveries for each type of general practitioner unit is shown in table I. Alongside units delivered significantly more women than either isolated or integrated units $(\mathrm{H}=43 \cdot 7, \mathrm{df}=2, \mathrm{p}<0 \cdot 001)$. This probably reflects the larger number of general practitioners having access to these units $(H=26.9$, $\mathrm{df}=2, \mathrm{p}<0.001$; median 25.5 for 44 integrated units, 66 for 20 alongside units and 15 for 55 isolated units), although the number of dedicated general practitioner beds did not differ significantly between the 62 isolated and 28 alongside units (median $8 v 10 \cdot 5 ; \mathrm{H}=3 \cdot 8, \mathrm{df}=1$, $\mathrm{p}>0.01$ ).

\section{TRANSFERS}

The numbers of women initially booked for general practitioner delivery and of transfers before and during labour are shown in table I. General practitioner alongside units booked significantly more women than either isolated or integrated units $(568 v 185$ and 106 respectively; $\mathrm{p}<0.001$ ). As would be expected, the actual numbers of transfers paralleled the number of bookings. Neither the percentage of women booked by general practitioners transferred before labour nor the percentage transferred during labour significantly differed among the three types of general practitioner unit. Also, taking all units together, there was no correlation between either the number of women booked by general practitioners and the percentage transferred before labour or the number of women booked by general practitioners and the percentage transferred during labour (Spearman rank coefficient $=0.086$ and 0.090 , respectively; $p>0.01$ ).

GENERAL PRACTITIONER INVOLVEMENT IN OBSTETRIC CARE AND AUDIT

Overall, 78 of 275 (28\%) units had at least one general practitioner clinical assistant in obstetrics, and $28(10 \%)$ had at least one hospital practitioner; the type of hospital was irrelevant. Consultant units were less likely to have any form of liaison committee for general practitioners and consultants $(14 / 35(40 \%) v 40 / 62$ $(65 \%)$ isolated units, $105 / 130(81 \%)$ integrated units, $25 / 28$ (89\%) alongside units; $p<0 \cdot 001$; table II). Of the 184 units with some form of committee, $93(51 \%)$ had a full maternity services liaison committee; in $28(15 \%)$ units the committee consisted of only general practitioners and consultants, and in $27(15 \%)$ it consisted of general practitioners, consultants, and midwives. Forty one committees $(26 \%)$ met at least every two months, $72(46 \%)$ met quarterly, and $44(28 \%)$ met less frequently.

Of 267 units, 196 stated that they audited their unit's results. General practitioners took part in this audit more commonly in isolated units (20/39 (51\%) $v 7 / 21$ (33\%) alongside units, $11 / 82$ (13\%) integrated units, $3 / 29(10 \%)$ consultant units; $p<0 \cdot 001$; table II). In particular, perinatal mortality meetings were held by 255 of 275 units. General practitioners did not take part in such meetings in $151(63 \%)$ of 240 units; they were significantly less involved in consultant units $(9 / 47$ $(19 \%) v 47 / 133$ (35\%) integrated units, 18/34 (53\%) isolated units, 15/26 (58\%) alongside units; $\mathrm{p}<0.01$; table II).

CONSULTANT INVOLVEMENT IN GENERAL PRACTITIONER OBSTETRICS

Of 210 units, $23(11 \%)$ required general practitioner obstetricians to possess the Diploma of the Royal College of Obstetricians and Gynaecologists, 82 (39\%) to have spent six months in a resident obstetric post, and $17(8 \%)$ to attend a minimum number of deliveries each year; there were no significant differences among different types of general practitioner unit. Consultants were more likely to determine whether a general practitioner was to be allowed to practise obstetrics in integrated units $(68 / 111(61 \%) v 8 / 40$ $(20 \%)$ isolated units, $5 / 19(26 \%)$ alongside units; $\mathrm{p}<0 \cdot 001$; table II).

Most units had written booking policies for general practitioner obstetricians, but general practitioners were less likely to have taken part in drawing up these policies in integrated units $(49 / 101(49 \%) v 37 / 53$ 
$(70 \%))$ isolated units, $19 / 23(83 \%)$ alongside units; $\mathrm{p}<0.01$; table II). Nearly half $(94,43 \%)$ of 218 units allowed general practitioners to induce labour for postmaturity, $81 \%$ allowed them to book primigravid women, and $35 \%$ allowed them to augment labour with oxytocin. The prevalence of these arrangements did not differ significantly in different types of general practitioner unit. In $110(54 \%)$ of 203 units general practitioners were allowed to use obstetric forceps, this practice being significantly more common in isolated units $47 / 57(82 \%) v$ 14/29 (48\%) alongside units, 49/117 $(42 \%)$ integrated units; $p<0.001$; table II).

\section{SUPPORT FACILITIES AND TRAINING}

Isolated units lacked support facilities. As might be expected, they hardly ever had an operating theatre available, but they were also less likely to have the use of a dedicated ultrasound scanner (19/64 (30\%)) $v$ $118 / 130(91 \%)$ integrated units, $44 / 49$ (90\%) consultant units, 25/28 (89\%) alongside units; $\mathrm{p}<0.001$; table III or fetal blood sampling equipment $(1 / 65(2 \%) v 92 / 131$ $(70 \%)$ integrated units, $19 / 27(70 \%)$ alongside units, $33 / 49(67 \%)$ consultant units; $p<0.001$; table III). Isolated units were significantly less likely to take par in training medical students $(3 / 64(5 \%) v 103 / 122$ $(84 \%)$ integrated units, $38 / 46(83 \%)$ consultant units, $21 / 29(72 \%)$ alongside units; $\mathrm{p}<0 \cdot 001$; table III)

\section{PROVISION OF DATA}

The three types of unit differed in their knowledge of their own activities. In all, 55 of $65(85 \%)$ isolated units and 20 of $29(69 \%)$ alongside units but only 72 $(54 \%)$ of 132 integrated units knew how many general practitioners had booking rights in their unit $\chi^{2}=17 \cdot 6$, $\mathrm{df}=2, \mathrm{p}<0.001)$. Forty two of $134(31 \%)$ integrated units knew how many women were transferred before labour from general practitioner to consultant care compared with 41 of $65(63 \%)$ isolated and 21 of 29 $(72 \%)$ alongside units $\left(\chi^{2}=27 \cdot 4, \mathrm{df}=2, \mathrm{p}<0 \cdot 001\right)$. For transfers during labour the figures were 59 of $134(44 \%)$ integrated units compared with 56 of $65(86 \%)$ isolated units and 28 of $29(97 \%)$ alongside units $\left(\chi^{2}=49 \cdot 5\right.$, $\mathrm{df}=2, \mathrm{p}<0 \cdot 001)$

\section{Discussion}

This is the first published survey of all maternity units in England and Wales to document extensively the participation of general practitioners in hospital obstetric care. It showed that general practitioners still provide some intrapartum care in four fifths of obstetric units in England and Wales, but it also confirmed the continuing decline of both general practitioner obstetrics ${ }^{4}$ and of isolated general practitioner maternity units. ${ }^{3}$ This decline in deliveries in isolated units has not been balanced by an increase in

TABLE III-Support facilities available in general practitioner units and consultant units. Figures are numbers (percentage) of units

\begin{tabular}{|c|c|c|c|c|c|c|}
\hline & \multicolumn{3}{|c|}{ General practitioner units } & \multirow{2}{*}{$\begin{array}{c}\begin{array}{c}\text { Consultant } \\
\text { units }\end{array} \\
\end{array}$} & \multirow[b]{2}{*}{$\mathrm{p}$ Value } & \multirow[b]{2}{*}{$\chi^{2}$} \\
\hline & Isolated & Alongside & Integrated & & & \\
\hline \multicolumn{7}{|c|}{ Unit has dedicated theatre: } \\
\hline Yes & 2 & 24 & 117 & 41 & $\mathrm{p}<0.001$ & $160(\mathrm{df}=3)$ \\
\hline No & 61 & 4 & 13 & 8 & & \\
\hline Not known & 2 & 1 & 4 & & & \\
\hline \multicolumn{7}{|c|}{ Unit has ultrasound scanner: } \\
\hline Yes & $19(30)$ & $25(89)$ & $118(91)$ & $44(90)$ & $\mathrm{p}<0.001$ & $98 \cdot 7(\mathrm{df}=3)$ \\
\hline No & $45(70)$ & $3(11)$ & $12(9)$ & $5(10)$ & & \\
\hline Not known & 1 & 1 & 4 & & & \\
\hline \multicolumn{7}{|c|}{ Unit has fetal blood sampling machine: } \\
\hline Yes & $1(2)$ & $19(70)$ & $92(70)$ & $33(67)$ & $\mathrm{p}<0.001$ & $92 \cdot 1(\mathrm{df}=3)$ \\
\hline No & $64(98)$ & $8(30)$ & $39(30)$ & $16(33)$ & & \\
\hline Not known & & 2 & 3 & & & \\
\hline \multicolumn{7}{|c|}{ Unit used for training medical students: } \\
\hline Yes & $3(5)$ & $21(72)$ & $103(84)$ & $38(83)$ & $\mathrm{p}<0.001$ & $126 \cdot 4(\mathrm{df}=3)$ \\
\hline No & $61(95)$ & $8(18)$ & $19(16)$ & $8(17)$ & & \\
\hline Not known & 1 & & 2 & 3 & & \\
\hline
\end{tabular}

deliveries in either alongside units or integrated units, and this is confirmed indirectly by the number of claims for payment that general practitioner obstetricians make to their family practitioner committees. We found that fewer than 10000 women were delivered in isolated general practitioner units, representing less than $1.6 \%$ of all deliveries reported to the survey.

Both the Royal College of Obstetricians and Gynaecologists and the Royal College of General Practitioners have suggested that general practitioners who provide intrapartum care should be better trained (possess the Diploma of the Royal College of Obstetricians and Gynaecologists and do six months' resident obstetrics) than those simply providing antenatal and postnatal care, and that they should attend a minimum number of deliveries each year to maintain their clinical experience. ${ }^{1214}$ Fewer than half the units reported adherence to these recommendations, and it is not clear what criteria, if any, potential general practitioner obstetricians have to fulfil to be approved. Furthermore, the recommendation to attend a minimum number of deliveries implies that general practitioners who book and attend only small numbers of confinements might provide substandard care because reduced exposure to clinical workload leads to erosion of their clinical acumen. This might then lead to increased uncertainty, which would be reflected in an increased rate of transfer. However, the percentage of women booked by general practitioners and transferred to consultant care is independent of both the type of general practitioner unit and the number of general practitioner bookings. This suggests that general practitioners' confidence is not eroded by working in small units. Confidence and competence are not, of course, synonymous, but Rosenblatt et al have shown that small units do not have an increased perinatal mortality rate. ${ }^{13}$

We believe that general practitioner units differ from each other in terms of general practitioners' involvement and commitment. In isolated and alongside units general practitioners are most involved in all aspects of the unit's management. In integrated units the power, not surprisingly, is held by the consultant staff; it is reasonable to infer that the relative lack of general practitioners' input into management and the small number of deliveries are causally linked. Alongside units would therefore seem to have advantages over integrated units, contrary to previous suggestion ${ }^{12}$ : they allow general practitioners to exert some influence over the management, clinical policies, and audit of the unit; to book women, safe in the knowledge that transfer will be fairly simple and trouble free; and to retain the identity of an individual unit, which is important to the staff of the unit and to the women who deliver in their care. According to this interpretation, the decision to concentrte facilities for general practitioner maternity care in integrated units can be seen as contributing to its eventual decline, however understandable it may have been. Isolated units seem to share with alongside units the sense of their own identity, and their smaller number of deliveries may reflect general practitioners' concern over the problems of transfer to a consultant unit.

If general practitioners are to continue providing full obstetric care in the future then their training should include experience in normal as well as abnormal pregnancy and labour. Therefore we regret the low level of training of medical students in isolated units, which seems to set them apart from other general practitioner units. In addition, we can not be sure that women booked by general practitioners are used for training in the other types of general practitioner unit, but we believe that they could be involved in providing excellent training for normal midwifery and "low tech" 
obstetrics, and it seems that this opportunity is not being fully used.

If general practitioners' responsibility for intrapartum care continues to decline then the relative lack of general practitioners' participation in liaison committees and perinatal mortality meetings, as is found now in consultant units, is the most likely pattern in the future. It is only through such bodies that general practitioners are likely to be able to influence care at any stage of pregnancy and to exercise any advocacy role. We may be witnessing not only the terminal decline of general practitioner intrapartum care but also the start of a long process in which general practitioners are excluded from having any say in obstetric care.

We thank Mr A O Hughes for statistical advice and Mrs J James for preparing the questionnaire. This work was supported by a grant from the Scientific Foundation Board of the Royal College of General Practitioners. LFPS is a research training fellow of the Royal College of General Practitioners.
2 Royal College of Obstetricians and Gynaecologists and the Population nvestigation Committee. Maternity in Great Britain. Oxford: Oxford University Press, 1948.

3 Campbell R, MacFarlane A. Where to be born? The debate and the evidence. Oxford: National Perinatal Epidemiology Unit, 1987.

4 Marsh GN, Cashman HA, Russell IT. General practitioner participation in intranatal care in the Northern region in 1983. BMf 1985;290:971-3.

5 Office of Population Censuses and Surveys. Birth statistics. London: HMSO 1988.

6 Bryce FC, Clayton JK, Rand RJ, Beck I, Farquharson DIM, Jones SE General practitioner obstetrics in Bradford. BMf 1990;300:725-7.

Lowe SW, House W, Garrett T. Comparison of outcome of low-risk labour in an isolated general practitioner maternity unit and a specialist maternity hospital. I R Coll Gen Pract 1987;37:484-7.

8 Prentice A, Walton SM. Outcome of pregnancies referred to a general practitioner unit in a district general hospital. BMf 1989;299:1090-2.

Young G. Are isolated maternity units run by general practitioners dangerous? BMY 1987;294:744-6.

10 Cavenagh AJM, Phillips KM, Sheridan B, Williams EMJ. Contribution of isolated general practitioner maternity units. $B M \mathcal{J}$ 1984;288:1438-40.

11 Sangala V, Dunster G, Bohin S, Osborne J. Perinatal mortality rates in isolated general practitioner maternity units. BMF 1990;301:418-20.

12 Royal College of Obstetricians and Gynaecologists. Report on the RCOG working party on antenatal and intrapartum care. London: RCOG, 1982.

13 Rosenblatt RA, Reinken J, Shoemack P. Is obstetrics safe in small hospitals? Lancet 1985; ii:429-32.

14 Royal College of Obstetricians and Gynaecologists and Royal College of General Practitioners. Report on training for obstetrics and gynaecology for general practice, a joint working party. London: RCOG, 1981 .
Epidemiology, Department

of Public Health and

Primary Care, University of

Oxford, Headington,

Oxford OX3 7LF

Christine Sellar, PHD, research officer

Joyce A Ferguson, PHD, national health fellow

(Canada)

Michael J Goldacre, FFCM, director

Correspondence to: Dr Sellar.

\title{
Occurrence and repetition of hospital admissions for accidents in preschool children
}

\author{
Christine Sellar, Joyce A Ferguson, Michael J Goldacre
}

\section{Abstract}

Objectives-To examine trends over time in the rates of admission to hospital for accidents of preschool children and to study patterns of repeated admissions for accidents in these children.

Design-Analysis of linked, routine abstracts of hospital inpatient records for accidents.

Setting-Six districts in the Oxford Regional Health Authority covered by the Oxford record linkage study.

Subjects-Records for 19427 children aged 5 years and under at the time of first recorded admission to hospital.

Main outcome measure-Number of admissions to hospital.

Results-Records were analysed in three groups: person based annual admission rates were calculated for each calendar year; each child's first recorded admission in 1976-85 was identified, and the child's record was followed up by linkage for one year from that admission; each child's first recorded admission in 1976-81 was identified and followed up for five years. Overall, 19427 children from an average annual resident population of 163000 children in 1976-86 had 20657 admissions for accidents before they were 6 years of age. Of these admissions 13983 were for injuries, 5717 for poisonings, and 957 for burns. Admission rates declined after 1976 for poisoning, but no substantial changes over time were found in admission rates for injuries or burns. A total of 17724 children were followed up for one year and 10889 for five years; $470(2.6 \%)$ of the children who were followed up for one year and $926(8.5 \%)$ of those followed up for five years had at least one further admission for an accident. Of those followed up for one year the 4 and 5 year old children were least likely and those under 1 and 1 year old were most likely to have a further admission for an accident. The number of children who had more than one accident was greater than would be expected if accidents were random occurrences. Those who had a poisoning at first admission were more likely to have another poisoning than an injury or burn; and those who had a burn at first admission were more likely to have another burn.

Conclusions-Hospital admissions for accidents in children are common: on average 1 child in 88 in this population was admitted each year. Multiple admissions are uncommon but none the less occur more often than would be expected by chance.

\section{Introduction}

Among children aged 1-14 years accidents are the commonest cause of death and account for one fifth of all hospital admissions in the United Kingdom. There is currently a high level of interest in efforts to reduce the incidence of accidents in childhood..$^{1-4}$

Many studies have been carried out to identify whether some children are at a greater risk of accidents than others. Studies of accident proneness, for example, have examined the characteristics of children who had more than one accident, their behaviour, ${ }^{56}$ families, and environment. ${ }^{57}$ There is evidence that children who have had an accident are at greater risk of a further accident than other children $^{89}$ and that admissions to hospital for injury in preschool children may help predict admission for injury in the next five years. ${ }^{10}$ An earlier study using data from the Oxford record linkage study showed that a study of admission rates and subsequent admissions analysed by type of accident would be useful ${ }^{8}$

We examined trends in admission rates over time among preschool children, the group at greatest risk of poisonings, burns, and home injuries, ${ }^{11}$ and describe here the occurrence and repetition of accidents. The term accident is used generically to include injuries, burns, and poisonings.

\section{Subjects and methods}

The Oxford record linkage study is a collection of brief abstracts of hospital inpatient records together with data from birth and death certificates. ${ }^{12}$ Data have 